\title{
Study and Clinical Application of the Anatomy of Renal Pedicles in Retroperitoneoscopic Nephrectomy
}

\author{
Estudio y Aplicación Clínica de la Anatomía de los \\ Pedículos Renales en la Nefrectomía Retroperitoneoscópica
}

Nan Zhang*; Zhongjie Shan*; Qianhe Han*; Kun Chen* \& Liang Guo*

\begin{abstract}
ZHANG, N.; SHAN, Z.; HAN, Q.; CHEN, K. \& GUO, L. Study and clinical application of the anatomy of renal pedicles in retroperitoneoscopic nephrectomy. Int. J. Morphol., 31(4):1153-1157, 2013.

SUMMARY: This work aims to investigate the anatomical basis and clinical application value of renal pedicle locating in retroperitoneoscopic nephrectomy. To summarize the anatomical basis of renal pedicle locating through retrospective analysis of 278 cases of retroperitoneoscopic nephrectomy from July 2007 to September 2009, during which renal pedicle was located at about 2-4 cm below the medial arcuate ligament of the diaphragm in the space between the psoas major muscle and inferior vena cava (abdominal aorta) in the anatomical level of space before psoas. The operation of 278 patients was all successfully completed, where renal pedicle was quickly found. It took $3.5 \pm 1.3 \mathrm{~min}$ to locate the renal pedicle, and $95.6 \pm 23.8 \mathrm{~min}$ to operate. In retroperitoneoscopic nephrectomy, it is most preferable to locate renal pedicle in the space before psoas. The renal pedicle is located exactly at about $2-4 \mathrm{~cm}$ below the medial arcuate ligament of the diaphragm in the space between the psoas major muscle and inferior vena cava (abdominal aorta). The time for locating the renal pedicle can be shortened if the surgeon is familiar with the anatomic features of renal pedicle in retroperitoneoscopy, thereby saving the operation time.
\end{abstract}

KEY WORDS: Laparoscopy; Nephrectomy; Anatomy; Retroperitoneoscopy.

\section{INTRODUCTION}

In recent twenty years, the application of retroperitoneoscopy in urinary surgery has been increasingly more mature, and more and more surgeons in this field treat kidney diseases such as nonfunctioning kidney and kidney neoplasms etc. using simple retroperitoneoscopic nephrectomy and radical nephrectomy (Kim et al., 2009; Taue et al., 2009; Chueh et al., 2011; Chung et al., 2011). Regardless of simple nephrectomy, radical nephrectomy, single incision laparoscopy or standard laparoscopy, the most critical step in the operation is how to fast and accurately find and correctly treat the renal pedicle vessels. Otherwise, it will be bound to extend the operation process, and increase the probability of renal vascular injury and conversion to open surgery (Pareek et al., 2006; Liapis et al., 2008; Ye et al., 2010; Sautter et al., 2011). Most of the current literature mainly report the advantages and oncologic effect of retroperitoneoscopic surgery and prevention of the complications (Ha et al., 2011; Pearce \& Subramaniam, 2011; Okegawa et al., 2012; Tepeler et al., 2012), but seldom report how to locate renal pedicles in retroperitoneoscopic operation (Sung \& Gill, 2002; Gao et al., 2008), and none of the literatures report the method of accurately locating the renal pedicles and its anatomical basis.

Through the 278 cases of retroperitoneoscopic nephrectomy, we have summarized the anatomical features of renal pedicle locating, thereby providing anatomical basis for fast finding renal pedicles.

\section{SUBJECT AND METHOD}

Clinical data. This group comprises 278 patients, including 148 male patients and 130 female patients with the average age of $54.7 \pm 16.5$ years old; 132 patients with renal carcinoma on the left side, and 146 patients on the right side; 117 patients with TINOMO renal carcinoma, 59 patients with T2NOMO renal carcinoma, 36 patients with upper urothelial cancer, and 66 patients with non-function in kidney. They all underwent preoperative B-type ultrasonic examination, $\mathrm{CT}$, electrocardiogram, chest radiograph, and routine

* Department of Urology, People's Hospital of Zhengzhou, Zhengzhou 450003, China. 
laboratory examination, and selectively underwent IVU and MR examination etc. This study was conducted in accordance with the declaration of Helsinki. This study was conducted with approval from the Ethics Committee of People's Hospital of Zhengzhou. Written informed consent was obtained from all participants.

Operation process. Anesthesia through endotracheal intubation. Before the operation, ureter and stomach tube were indwelled, and the waist bridge of the patients was heightened in lateral position of healthy side. Retroperitoneal space was set up and cannula was placed according to the method given in the literatures (Gill et al., 2000; Zhang et al., 2005). $\mathrm{CO}_{2}$ pressure in the retroperitoneum was $12 \sim 15 \mathrm{mmHg}(1 \mathrm{mmHg}=0.133 \mathrm{kPa})$. For patients with renal malignant tumors, first we dissociated the back side of their kidney in the space before psoas, and located and treated the renal pedicle vessels. Secondly, we dissociated the lower pole of their kidney at the renal pyramid tip and treated the ureter and gonad vessels. Thirdly, we dissociated the upper pole of the kidney in the space between the diaphragm fascia and perirenal fascia. Finally, we dissociated the ventral side of the kidney in the space between perirenal fascia and fusion fascia. For simple nephrectomy, we first located and treated their renal pedicle in the space before psoas, and then successively dissociated the ventral side, lower pole and upper pole of their kidney in the space without vessels between perirenal fascia and perirenal fat. We treated the ureter and gonad vessels when dissociating the lower pole, and treated adrenal gland vessels on the same side when dissociating the upper pole, with the adrenal gland completely retained. Drainage tube was regularly indwelled, and the sample was put in a bag. Incision of linea axillaris anterior below costal margin was extended longitudinally, the muscle layer was separated to take out the kidney. For the operation of the patients with upper urothelial carcinoma, the kidney was not immediately taken out, an oblique incision was made on the lower abdomen at the same side of the patient in horizontal position to exsect the ureter in full length, exsect the bladder in the form of a sleeve, remove the complete kidney and ureter, and respectively place a drainage tube around the nephridial pit and bladder.

Locating and treatment of renal pedicles: first, we located the psoas major muscle and extraperitoneal fat in the retroperitoneum, cut open the lateral conical fascia on the surface of musculus quadratus lumborum using ultrasonic scalpels to enter the space before psoas. Then we dissociated external side and back side of the kidney, extending up to crura of external diaphragm and down to conical tip in the posterior layer of Gerota fascia. We dissociated along the surface of psoas major muscle deeply to its medial border, and then, cut open the perirenal fascia in the middle of the kidney at about $2 \sim 4 \mathrm{~cm}$ below the medial arcuate ligament of the diaphragm in the space between psoas major muscle and inferior vena cava (abdominal aorta). Then, the pulsing, rising and thick cord-like renal pedicles wrapped in fibrous tissue (vagina vasorum) can be seen. After cutting open the fibrous tissue using ultrasonic scalpels, we can see white renal artery, under the front of which is the vein. By combined use of ultrasonic scalpels, suction apparatus and right-angle forceps, we first dissociated the renal artery by $2 \sim 3 \mathrm{~cm}$ along its extending direction, blocked it using three Hem-o-lok, with two at proximal end and one at distal end, and cut the artery. Here, profile of the renal vein was clearly seen. Observe whether the renal veins were collapsed and became atrophied. If they were still full, the possibility of several renal arteries and accessory renal arteries was considered in the light of the preoperative iconographical examination, and the renal veins were treated on completion of the treatment of renal artery branches. We cut open the sheath of renal veins, dissociated about $2 \sim 3 \mathrm{~cm}$ length along its extending direction, and treated the renal veins in the same way as renal artery.

Observation indexes. The observation indexes include the time for locating renal pedicles, operation duration, estimated amount of bleeding in operation process, postoperative dosage of acesodyne, time for postoperative recovery of diet, ambulation time, postoperative drainage, time for removing the postoperative drainage tube, number of days of postoperative hospitalization, and probability of occurrence of complications during and after operation etc. The time for locating renal pedicles is defined as the time from cutting open the lateral conical fascia to seeing renal pedicle vessels, and the operation duration is defined as the time from cutting open the skin to closing the incision.

\section{RESULTS}

General data. The operation of all 278 patients was successfully completed without conversion to open operation and blood transfusion. 5 patients suffered from peritoneal rupture, which was occluded using Hem-o-lok when it was small, and sutured when it was large, but it did not affect the operation progress. The average time for locating renal pedicles was $3.5 \pm 1.3 \mathrm{~min}$, the operation duration was $95.6 \pm 23.8 \mathrm{~min}$, the amount of bleeding in operation process was $72.4 \pm 27.5 \mathrm{ml}$, the postoperative dosage of pethidine was $55 \pm 27 \mathrm{mg}$, median value of postoperative drainage was 110 (30 300) $\mathrm{ml}$, time for removing the drainage tube was $3.7 \pm 1.2 \mathrm{~d}$, the time for recovery of diet was $2.1 \pm 0.7 \mathrm{~d}$, the ambulation time was $1.8 \pm 0.9 \mathrm{~d}$, and the postoperative 


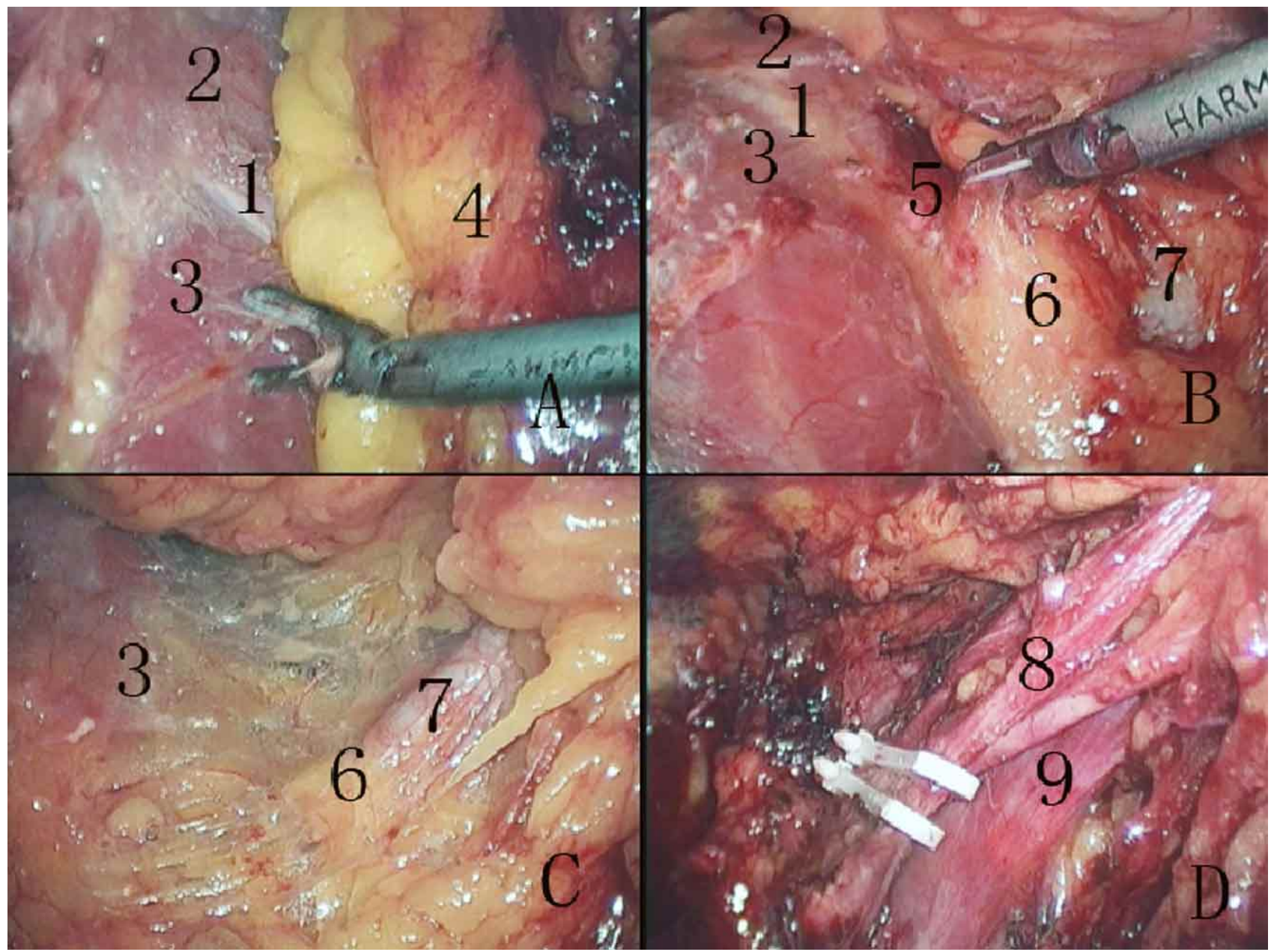

Fig. 1. Anatomic features of renal pedicle in retroperitoneoscopic nephrectomy. A. Space before psoas; B. Position relationship between the right renal pedicle and medial arcuate ligament of right diaphragm; C. Visual features of renal pedicles; D. Position relationship between right renal artery (three) and vein. 1. Medial arcuate ligament; 2. Diaphragm; 3. Psoas major muscle and its fascia; 4 . Posterior lobe of perirenal fascia; 5. Shallow ridge; 6 . Thin fat; 7. Renal pedicle; 8. Renal artery; 9. Renal vein.

hospitalization last for $8.5 \pm 2.7$ d. 12 patients had slight postoperative shoulder pain, which disappeared automatically after $1 \sim 2 \mathrm{~d}$.

Postoperative follow-up. One hundred eighty three patients were followed up, and the median follow-up time was 18 (6 38) months. None of them had tumor recurrence, incisional implantation, incisional hernia or other long-term complications.

\section{DISCUSSION}

Since Gaur et al. (1993) completed the first retroperitoneoscopic nephrectomy in 1993, retroperitoneoscopic nephrectomy is increasingly widely applied. At present, it has become the main choice for treatment of kidney diseases such as nonfunctioning kidney and kidney neoplasms etc. The treatment of renal pedicle vessel is a key step in the whole retroperitoneoscopic nephrectomy (Al-Qudah et al., 2007; Hsiao \& Pattaras, 2008; Liapis et al.), and the treatment speed of renal pedicle vessel directly affects the operation process. Improper treatment, if any, will cause uncontrolled bleeding, and can only be converted to open surgery (Sautter et al.; Pareek et al.; Liapis et al.; Takaaki et al., 2010; Ye et al.).

Through clinical practice of 278 cases of retroperitoneoscopic nephrectomy, we summarized the anatomic features of renal pedicles: 1) It is most preferably to locate renal pedicles in the space before psoas (Fig. 1A): No matter for radical nephrectomy or simple nephrectomy, it is necessary to locate renal pedicles in the anatomic level 
of the space before psoas (between posterior lobes of psoas fascia and perirenal fascia). The video data of operation of 278 patients showed that there is neither vessel, nor adipose tissue etc. at this level, and there is only a little white loose fibrous tissue. Literatures (Hsiao \& Pattaras; Gupta et al., 2008) also stressed that in retroperitoneoscopic nephrectomy, it is necessary to treat renal pedicle vessels outside the perirenal fascia in the space before psoas. 2) The renal pedicle is exactly located at about $2-4 \mathrm{~cm}$ below the medial arcuate ligament of the diaphragm in the space between the psoas major muscle and inferior vena cava (abdominal aorta) in the center of the kidney (Fig. 1B). After dissociating the space before psoas, a longitudinal "shallow ridge (the space between the psoas major muscle and inferior vena cava or abdominal aorta)" is clearly seen in the medial border of the psoas major muscle. In the upper part of the psoas major muscle, there is a silver white arcuate fibrous tissue, namely the medial arcuate ligament of the diaphragm. Below the medial arcuate ligament in the "shallow ridge", the renal pedicle is located on an obviously rising site covered with thin fat, which is equivalent to the middle of the kidney. 3) The visual features of renal pedicles in retroperitoneoscopic nephrectomy are rising, pulsing, thick cord-like, transverse, wrapped in fibrous tissue and covered with thin adipose tissue (Fig. 1C). What is first seen is the apparently rising tissue structure covered with thin fat in the shallow ridge, and there is visible pulse in its medial side. After pushing aside the thin fat on its surface, profile of the transversely extending renal artery wrapped in fibrous tissue can be clearly seen. After cutting open the fibrous tissue (vagina vasorum), the renal artery is fully exposed, and the vein is under the front of the artery (Fig. 1D). The surgeons usually pay greatest attention to the arteriorenal pulse, and often locate the renal artery by this feature. But our observations showed that before cutting open the renal artery sheath, its pulse range is relatively large, especially on the left side, it is sometimes very difficult to accurately judge the position of renal artery by pulse due to the interference of the abdominal aorta. In addition, the arteries of non-functioning kidney are often atrophied and thinned, or even occluded, to different extents, and have weak pulse or even no pulse. In 66 patients with non-functioning kidney in this group, there are 27 patients with weak arteriorenal pulse $(40.9 \%)$, and 13 patients without significant pulse (19.7\%).

In conclusion, in retroperitoneoscopic nephrectomy, it is most preferably to locate renal pedicle in the space before psoas. The renal pedicle is exactly located at about $2-4 \mathrm{~cm}$ below the medial arcuate ligament of the diaphragm in the space between the psoas major muscle and inferior vena cava (abdominal aorta). The time for locating the renal pedicle can be shortened if the surgeon is familiar with the anatomic features of renal pedicle in retroperitoneoscopy, thereby saving the operation time and reducing injury to the patients.

ZHANG, N.; SHAN, Z.; HAN, Q.; CHEN, K. \& GUO, L. Estudio y aplicación clínica de la anatomía de los pedículos renales en la nefrectomía retroperitoneoscópica. Int. J. Morphol., 31(4):1153-1157, 2013.

RESUMEN: El objetivo del estudio fue investigar las bases anatómicas y el valor de la aplicación clínica de la localización del pedículo renal en la nefrectomía retroperitoneoscópica. Para resumir las bases anatómicas de la localizacion del pedículo renal se realizó el análisis retrospectivo de 278 casos de nefrectomía retroperitoneoscópica desde Julio del 2007 a Septiembre del 2009. El pedículo renal se encontró a unos 2-4 cm por debajo del ligamento arqueado medial del diafragma en el espacio entre el músculo psoas mayor y vena cava inferior (o parte abdominal de la aorta) en el nivel anatómico del espacio anterior al músculo psoas mayor. La cirugía de los 278 pacientes fue

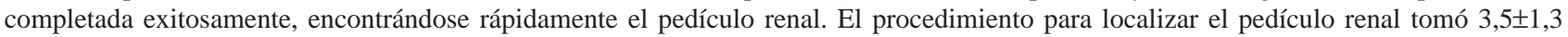
minutos y la cirugía completa $95.6 \pm 23.8$ minutos. En la nefrectomía retroperitoneoscópica, es preferible localizar el pedículo renal en el espacio anterior al músculo psoas mayor. El pedículo renal se encuentra alrededor de $2-4 \mathrm{~cm}$ por debajo del ligamento arqueado medial de la membrana en el espacio entre el músculo psoas mayor y vena cava inferior (parte abdominal de la aorta). El tiempo para localizar el pedículo renal se puede disminuir si el cirujano está familiarizado con las características anatómicas del pedículo renal en la retroperitoneoscopía, ahorrando así el tiempo total de la cirugía.

PALABRAS CLAVE : Laparoscopía; Nefrectomía; Anatomía; Retroperitoneoscopía.

\section{REFERENCES}

Al-Qudah, H. S.; Rodriguez, A. R. \& Sexton, W. J. Laparoscopic management of kidney cancer: updated review. Cancer Control, 14(3):218-30, 2007.

Chueh, S. C.; Sankari, B. R.; Chung, S. D. \& Jones, J. S. Feasibility and safety of retroperitoneoscopic laparoendoscopic single- site nephrectomy: technique and early outcomes. BJU Int., 108(11):1879-85, 2011.

Chung, S. D.; Huang, C. Y.; Tsai, Y. C.; Chueh, S. C.; Hung, S. F.; Wang, S. M.; Liao, C. H. \& Yu, H. J. Retroperitoneoscopic laparo-endoscopic single-site radical nephrectomy (RLESS- 
RN): initial experience with a homemade port. World J. Surg. Oncol., 9:138, 2011.

Gao, J.; Guo, G.; Jie, Z.; Wei, W.; Xu, A.; Dong, J. \& Hong, B. A fast method to identify renal vessels during retroperitoneal laparoscopic nephrectomy. J. Endourol., 22(8):1705-8, 2008.

Gaur, D. D.; Agarwal, D. K. \& Purohit, K. C. Retroperitoneal laparoscopic nephrectomy: initial case report. J. Urol., 149(1):103-5, 1993

Gill, I. S.; Schweizer, D.; Hobart, M. G.; Sung, G. T.; Klein, E. A. \& Novick, A. C. Retroperitoneal laparoscopic radical nephrectomy: The Cleveland clinic experience. J. Urol., 163(6):1665-70, 2000.

Gupta, N. P.; Hemal, A. K.; Mishra, S.; Dogra, P. N. \& Kumar, R. Outcome of retroperitoneoscopic nephrectomy for benign nonfunctioning kidney: a single-center experience. $J$. Endourol., 22(4):693-8, 2008.

Ha, U. S.; Hwang, T. K.; Kim, Y. J.; Oh, T. H.; Jeon, Y. S.; Lee, W.; Lim, J. S.; Lee, T. Y.; Choi, Y.; Park, S. K. \& Byun, S. S. Comparison of oncological outcomes of transperitoneal and retroperitoneal laparoscopic radical nephrectomy for the management of clear-cell renal cell carcinoma: a multiinstitutional study. BJU Int., 107(9):1467-72, 2011.

Hsiao, W. \& Pattaras, J. G. Not so "simple" laparoscopic nephrectomy: outcomes and complications of a 7-year experience. J. Endourol., 22(10):2285-90, 2008.

Kim, C.; McKay, K. \& Docimo, S. G. Laparoscopic nephrectomy in children: systematic review of transperitoneal and retroperitoneal approaches. Urology, 73(2):280-4, 2009.

Liapis, D.; de la Taille, A.; Ploussard, G.; Robert, G.; Bastien, L.; Hoznek, A.; Vordos, D.; Abbou, C. \& Salomon, L. Analysis of complications from 600 retroperitoneoscopic procedures of the upper urinary tract during the last 10 years. World J. Urol., 26(6):523-30, 2008.

Okegawa, T.; Itaya, N.; Hara, H.; Nutahara, K. \& Higashihara, E. Initial operative experience of single-port retroperitoneal laparoscopic nephrectomy. Int. J. Urol., 19(8):778-82, 2012.

Pareek, G.; Hedican, S. P.; Gee, J. R.; Bruskewitz, R. C. \& Nakada, S. Y. Meta-analysis of the complications of laparoscopic renal surgery: comparison of procedures and techniques. J. Urol., 175(4):1208-13, 2006.

Pearce, R. \& Subramaniam, R. Minimally invasive partial or total nephrectomy in children: a comparison between transperitoneal and retroperitoneal approaches. Pediatr. Surg. Int., 27(11):1233-7, 2011.

Sautter, T.; Haueisen, H.; Stierli, P.; Kwiatkowski, M. \& Recker, F. A severe complication of retroperitoneoscopic nephrectomy. J. Urol., 165(2):515-6, 2001.
Sung, G. T. \& Gill, I. S. Anatomic landmarks and time management during retroperitoneoscopic radical nephrectomy. J. Endourol., 16(3):165-9, 2002.

Takaaki, I.; Kinoshita, H.; Satou, M.; Oguchi, N.; Kawa, G.; Muguruma, K.; Murota, T. \& Matsuda, T. Complications of urologic laparoscopic surgery: a single institute experience of 1017 procedures. J. Endourol., 24(2):253-60, 2010.

Taue, R.; Izaki, H.; Koizumi, T.; Kishimoto, T.; Oka, N.; Fukumori, T.; Takahashi, M. \& Kanayama, H. O. Transperitoneal versus retroperitoneal laparoscopic radical nephrectomy: a comparative study. Int. J. Urol., 16(3):263-7, 2009.

Tepeler, A.; Akman, T.; Tok, A.; Kaba, M.; Binbay, M.; Müslümanog `lu, A. Y. \& Tefekli, A. Retroperitoneoscopic nephrectomy for non-functioning kidneys related to renal stone disease. Urol. Res., 40(5):559-65, 2012.

Ye, Z.; Xi, Q.; Wang, S.; Liu, J.; Song, X. \& Yu, X. Pure retroperitoneoscopic surgery versus minimal incision-assisted retroperitoneoscopic surgery for upper urinary tract diseases. J. Endourol., 24(6):993-6, 2010.

Zhang, X.; Zheng, T.; Ma, X.; Li, H. Z.; Li, L. C.; Wang, S. G.; Wu, Z. Q.; Pan, T. J. \& Ye, Z. Q. Comparison of retroperitoneoscopic nephrectomy versus open approaches to nonfunctioning tuberculous kidneys: a report of 44 cases. $J$. Urol., 173(5):1586-9, 2005.

\section{Corresponding to: \\ Nan Zhang \\ Department of Urology \\ People's Hospital of Zhengzhou \\ Zhengzhou 450003 \\ CHINA}

Tel: +86-371-67077010

Fax: $+86-371-67077010$

Email: nanzhangcn@163.com

Received: 07-03-2013

Accepted: 11-08-2013 